\title{
POINTS IN THE TECHNIQUE OF RECEMENTING IN THE REVISION OF AN IMPLANT ARTHROPLASTY
}

\author{
A. SETH GREENWALD, NATHANIEL C. NARTEN, ALAN H. WILDE \\ From the Department of Orthopaedic Surgery, The Cleveland Clinic Foundation, Cleveland
}

\begin{abstract}
When aseptic failure of the bond between the cement and the prosthesis of a total joint replacement occurs, complete removal of the cement has been advocated before the insertion of a new prosthesis. The present study questions this practice. Both laboratory tests on variously prepared specimens of cement and clinical experiences demonstrate that recementing over old cement is a practical alternative if the technique employed includes the removal of blood from the old cement surface, rasping of this surface and the early application of fresh cement.
\end{abstract}

As Charnley wrote in 1965, "The making of a permanent bond between an inert surgical implant and a living bone which will remain sound even though transmitting the forces produced by the weight of the body is one of the most urgent subjects for research in modern orthopaedics".

Thirteen years later the abundant use of acrylic bone cement would suggest that this goal has been achieved. However, with the passage of time, increasing numbers of late failures of a total joint system have become manifest. Loosening in the presence of sepsis is believed to be due to the infectious process itself (Galante 1971; Coventry 1975). On the other hand aseptic late failures, shown by structural failure of the implant or by loosening at one or other or both of the interfaces between the cement and either the bone or the implant, are believed to be secondary to faulty surgical technique (Amstutz 1970; Charnley 1970; Galante 1971; Eftekhar 1974).

In a case of aseptic late failure of the bond between prosthesis and cement, revision is often considered. Removal of all the old bone cement is generally advocated (Chapchal, Sloof and Nollen 1973), but this can be time-consuming and even hazardous, as is well known by anyone who has attempted it.

This study questions such practice. It investigates, quantitatively, the strength of the bond between old hard and freshly polymerised cement and describes a technique of enhancing this.

\section{MATERIALS AND METHODS}

The study employed Surgical Simplex $P$ with 10 per cent barium sulphate. ${ }^{*}$ The goals of the methods of testing were to evaluate (a) the mechanical properties of uniformly polymerised solid masses of acrylic cement in order to establish control indices; (b) the effect of various preparations of the surface on the strength of the interface between masses of old and new cement; (c) the effect of lamination on the strength of freshly polymerised cement; and (d) the effect of the time of preparation of the new cement on the interface strength between old and new cement.

Uniformly polymerised specimens. Fresh cement was prepared by manual mixing in a porcelain bowl for three minutes at 120 beats per minute. This frequency was chosen because it was approximately that employed by our operating room nurses. This was carried out at an ambient temperature of $21^{\circ} \mathrm{C}$ and a relative humidity of 27 per cent.

${ }^{*}$ Howmedica, Inc., Medical Division, Rutherford, New Jersey.

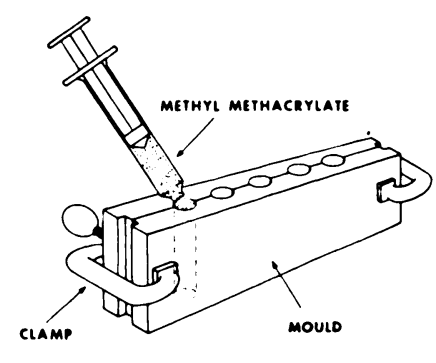

Fig. 1

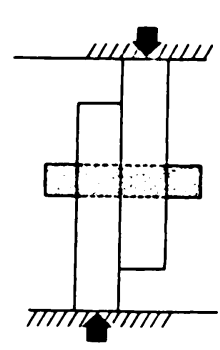

Fig. 2

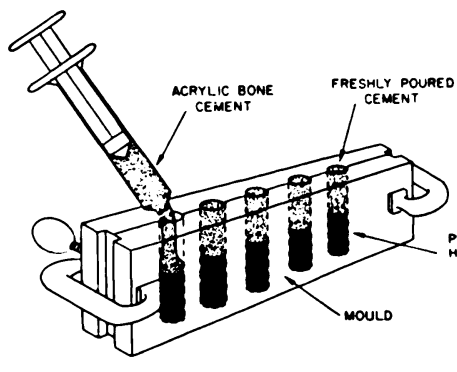

Fig. 3

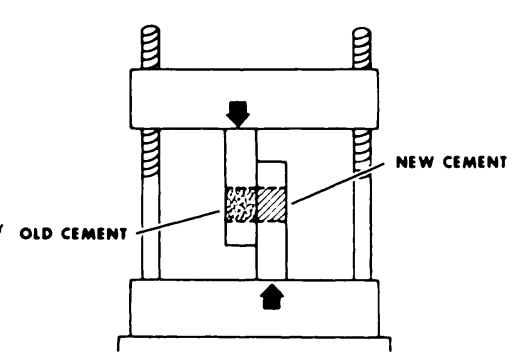

Fig. 4

Figure 1-Specimen preparation for determining the shear strength of uniform acrylic cement cylinders. Figure 2-Diagram indicating test arrangement for determining the shear strength of acrylic bone cement specimens. Figure 3-Preparation of composite acrylic cement specimens. Figure 4-Diagram indicating test arrangement for determining the shear strength between freshly polymerised and previously hardened acrylic bone cement.

A. Seth Greenwald, M.D., Director, Biomechanics Laboratory Nathaniel C. Narten, M.D., Department of Orthopaedic Surgery Alan H. Wilde, M.D., Chairman, Department of Orthopaedic Surgery
Cleveland Clinic Foundation, 9500 Euclid Avenue, Cleveland, Ohio 44106, United States of America. 
The doughy mass was placed in a modified syringe and injected into cylindrical metal moulds 0.5 inches in diameter and 1.5 inches deep (Fig. 1). After polymerisation, the specimens were trimmed of excess cement, measured for average diameter, and cured in air for eight days at $21^{\circ} \mathrm{C}$. They were then fitted into a pair of offset stainless steel blocks with half-inch holes representing a single shear test configuration. The system was placed in an Instron Testing Machine and loaded at a crosshead speed of 0.5 inches per minute until failure (Fig. 2).

Surface preparation. In order to compare the effect of various preparations of the surface of the old cement on the strength of an oldnew cement interface, composite specimens were made. Steel plugs 0.75 inch in length were inserted into the lower half of the cylindrical mould, shown in Figure 1, and acrylic cement prepared as described was then injected, producing the other half of a composite specimen. After curing for one week, the contact surface of each specimen of cement was either coated with blood, left clean, or roughened with a rasp. They were then reversed into the moulds and freshly polymerising cement was injected on top of the variously prepared interfaces (Fig. 3). After further curing for a week, the specimens were tested in a similar manner to that already described (Fig. 4).

Table I. Shear force at failure for singly poured and composite specimens

\begin{tabular}{|l|c|c|c|c|}
\hline Test configuration & $\begin{array}{c}\text { Number } \\
\text { of } \\
\text { specimens }\end{array}$ & $\begin{array}{c}\text { Mean shear } \\
\text { strength } \\
\left.\text { (lbs/in }^{2}\right)\end{array}$ & $\begin{array}{c}\text { Standard } \\
\text { deviation }\end{array}$ & $\begin{array}{c}\text { Coefficient } \\
\text { of variation } \\
\text { (per cent) }\end{array}$ \\
\hline Uniform cylinders & 8 & 5975 & 155 & 3 \\
$\begin{array}{l}\text { Composite cylinders } \\
\text { with blood interface }\end{array}$ & 8 & 3745 & 643 & 17 \\
$\begin{array}{l}\text { Composite cylinders } \\
\text { with clean interface }\end{array}$ & 8 & 5047 & 542 & 11 \\
$\begin{array}{l}\text { Composite cylinders } \\
\text { with rasped interface }\end{array}$ & 9 & 5588 & 374 & 7 \\
\hline
\end{tabular}

Laminated specimens. The effect of lamination on the interface strength of specimens made from freshly polymerised cement was evaluated by filling each half of the shear blocks simultaneously and then pressing together in an offset position until polymerisation. The specimens were again cured and tested as described above.

The effect of preparation time. The interface strength between new and old cement was determined by varying the preparation time of the fresh cement from three to nine minutes. The weight loss of the monomer-polymer mixture over this interval was also recorded and correlated with the resulting interface strength of the composite specimens, which were prepared and tested in the same manner as previously described.

\section{RESULTS}

All specimens exhibiting defects or bubbles on the old cement surface and those tested composite specimens which showed voids or bubbles in the plane of shear were discarded because an accurate measurement of their surface area of contact could not be made and because of the fact that if the shear plane did pass through one of these voids, then a falsely low shear stress would be recorded. For the remainder, the main shear strength was obtained by dividing the shear force at failure by the cross-sectional area of the specimen.

$$
\underset{\left(\mathrm{lbs} / \mathrm{in}^{2}\right)^{*}}{\text { Mean sth }}=\frac{\text { Shear force at failure (lbs) }}{\text { Cross-sectional area }\left(\mathrm{in}^{2}\right)}
$$

*To express yalues of shear strength in $\mathrm{kg} / \mathrm{cm}^{2}$, multiply by 0.07 .

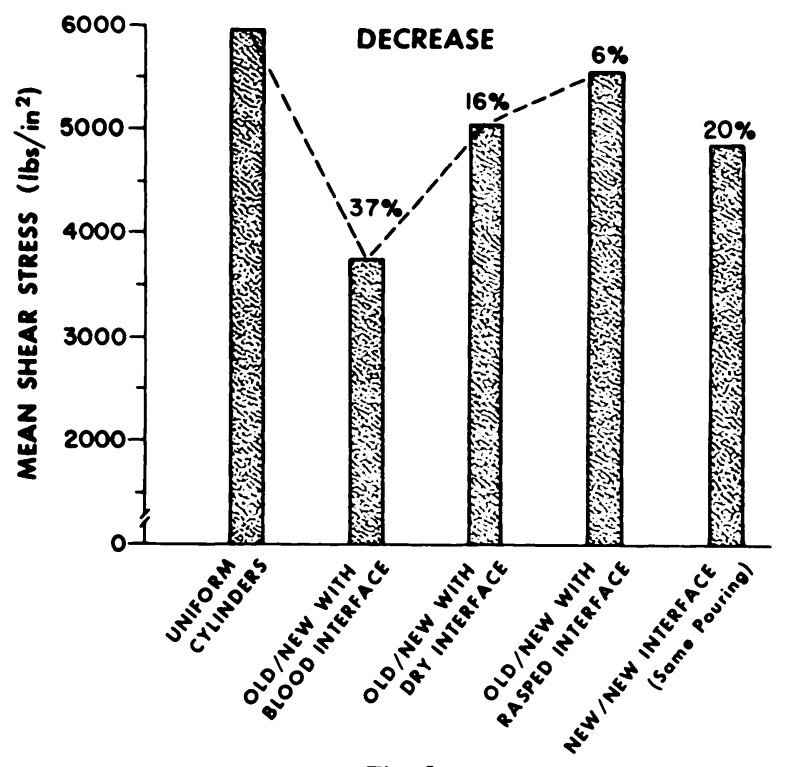

Fig. 5

The effect of different interfaces on the shear strength of Surgical Simplex P.

Uniform and composite specimens. The results of these tests are summarised in Table $I$, and are displayed graphically in Figure 5. Compared with the strength of the uniform cylinders, the composite cylinders with blood at the interface showed a reduction of 37 per cent, those free of blood at the interface a reduction of 16 per cent, while those both free of blood and rasped before the application of fresh cement showed a decrease of only 6 per cent.

Laminated specimens. The results here indicated a decrease of interface strength by 20 per cent (Fig. 5).

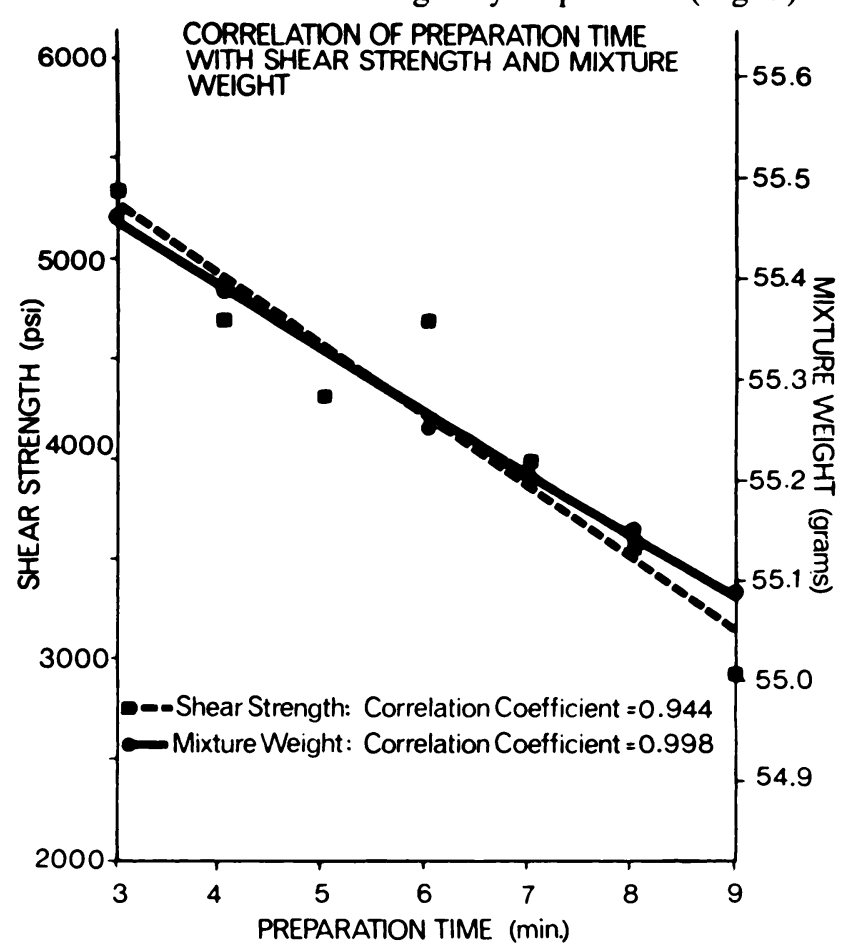

Fig. 6

Correlation of preparation time with shear strength and mixture weight. 
The effect of preparation time. The effect on the interface strength between new and old cement is illustrated in Table II and Figure 6. The interface strength of the nine-minute specimens was 82 per cent less than those of the three-minute specimens. A least square analysis of the data describes a linear inverse relationship between preparation time and shear

\section{CLINICAL SIGNIFICANCE}

As originally stressed by Charnley and later by many others, sound techniques for the use of acrylic cement in implant arthroplasty procedures are of major importance in the prevention of subsequent loosening of the components. Our laboratory findings have provided quantitative evidence that the presence of lamination in

Table II. Old-new bone cement interface shear strength at various preparation times

\begin{tabular}{|c|c|c|c|c|c|}
\hline $\begin{array}{c}\text { Preparation } \\
\text { time } \\
(\text { min })\end{array}$ & $\begin{array}{c}\text { Number } \\
\text { of } \\
\text { specimens }\end{array}$ & $\begin{array}{c}\text { Mean shear } \\
\text { strength } \\
\left.\text { (lbs/in }^{2}\right)\end{array}$ & $\begin{array}{c}\text { Standard } \\
\text { deviation }\end{array}$ & $\begin{array}{c}\text { Coeficient } \\
\text { of variation } \\
\text { (per cent) }\end{array}$ & $\begin{array}{c}\text { Percentage } \\
\text { difference }\end{array}$ \\
\hline 3 & 7 & 5322 & 520 & 10 & \\
4 & 8 & 4686 & 365 & 8 & -12 \\
5 & 9 & 4309 & 924 & 21 & -19 \\
6 & 10 & 4684 & 382 & 8 & -12 \\
7 & 9 & 3985 & 747 & 19 & -34 \\
8 & 9 & 3556 & 560 & 16 & -33 \\
9 & 10 & 2924 & 716 & 24 & -82 \\
\hline
\end{tabular}

strength (correlation coefficient 0.944 ). The loss of monomer-polymer mixture weight was found to be linear over the time span studied (correlation coefficient 0.998). This line is nearly parallel to that of the shear strength versus time plot. The loss of mixture weight of the mix is believed to be primarily due to evaporation of monomer (Lee and Ling 1975). Hence, a relationship between loss of monomer from the monomer-polymer mixture of the new cement and the loss of shear strength between old and new cement can be proposed and tested statistically by plotting one against the other (Fig. 7). Again, a linear relationship was found, with a correlation coefficient of 0.926 .

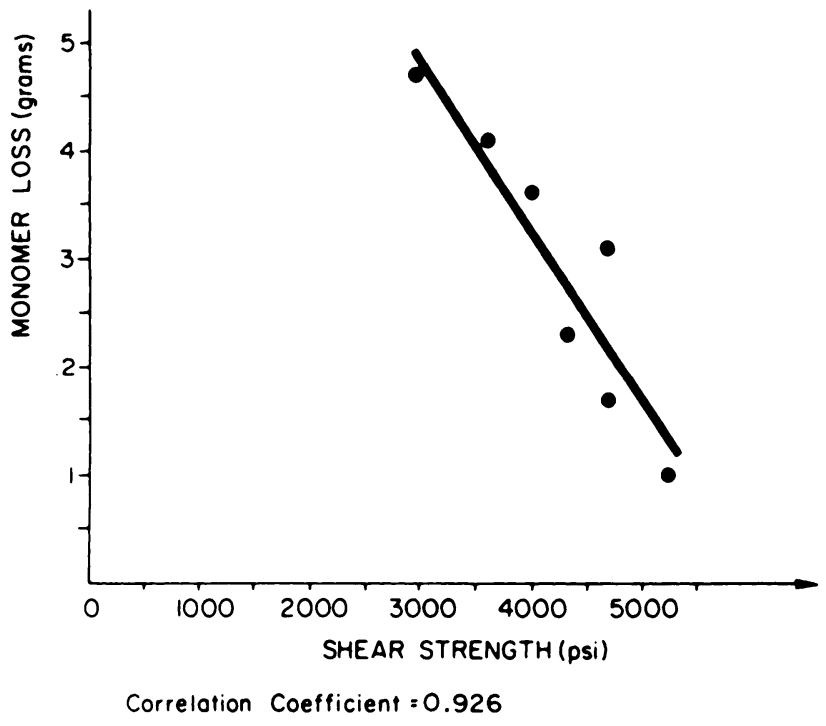

Fig. 7

Correlation between monomer loss and shear strength. acrylic bone cement significantly decreases its strength. The inference is that the application of the cement in one mass may be important in preventing late failure. The following case is relevant.

A radiograph was taken after suspected loosening of a geomedic total knee replacement cemented with Surgical Simplex $P$ without barium (Fig. 8). In this case the surgeon had placed cement first on the tibial component and then on the tibia itself, after which he pressed the two masses together. An arthrogram showed a transverse line in the medial side of the tibial component indicating penetration of dye between the two layers of cement (Fig. 9). At revision loosening at the laminar interface was confirmed (Fig. 10).

This case illustrates the consequence of producing laminations in the cement during the insertion of a prosthesis. It is therefore deemed essential that the cement be applied in one mass.

The increasing prevalence of late aseptic failure of total joint replacements raises the question whether complete removal of the cement is necessary in every case of revision. It has been suggested that all old cement be removed before recementing (Chapchal et al. 1973). However, the difficulties of complete removal, the risk of a fracture, of interruption of blood supply and of reduction in the amount of remaining cancellous bone, which is the basis for interdigitation of the bonecement bond may together represent a greater risk than that of bond failure at an old-new cement interface. In the replacement of a non-infected femoral prosthesis, Charnley recommends merely reaming out sufficient cement to permit a loose fit of the new prosthesis (Charnley 1976).

The laboratory studies demonstrate that the practice of recementing over a previously hardened 


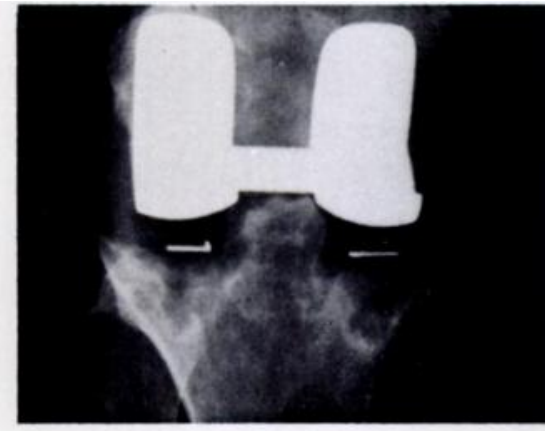

Fig. 8

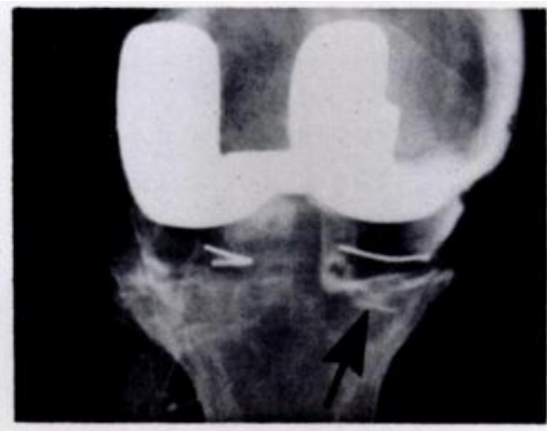

Fig. 9

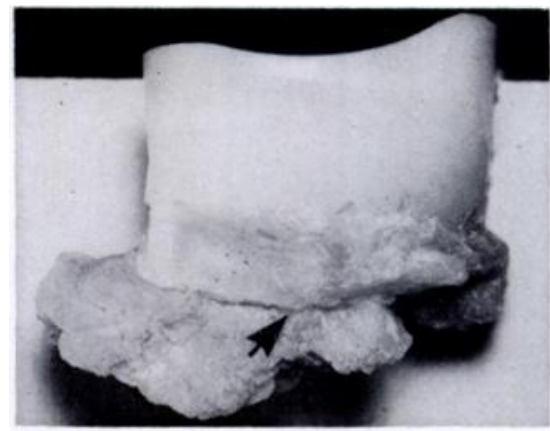

Fig. 10

Figure 8-Radiograph of geomedic prosthesis without barium in the cement. Figure 9-The arthrogram of the same knee clearly shows a transverse line indicating dye between layers of cement. Figure 10-Loosening of this tibial prosthesis occurred at the lamination interface where cement had been applied separately to the surfaces of the tibia and of the prosthesis.

cement mass is a practical alternative to complete removal. A clinical technique described by Lowell adds support to this concept (Lowell 1974). He found that when a batch of cement already placed proved inadequate to fill the femoral shaft, good fixation could be attained by creating a large recess in the soft cement with the stem of the prosthesis, and after its polymerisation, adding a second batch of cement before the final insertion of the femoral component. This technique has a result similar to that of the old-new half cylinders shown in Figure 5. The trend indicated by the dotted line in this figure demonstrates the effectiveness of two techniques employed to achieve bond enhancement at an old-new cement interface. The first requires the absence of blood, the second requires rasping of the surface. This gives an interface strength closely approaching that of acrylic cement poured in one mass.

It is interesting to note that although the experiments described here concern Surgical Simplex $\mathbf{P}$ with barium, similar results have been obtained in our laboratory with several other cements-Surgical Simplex $\mathbf{P}$ without barium, CMW Sulfix, Palacos with and without gentamicin (Greenwald et al. 1975). These cements yielded composite strengths ranging from 7 to 24 per cent below that of singly poured specimens. This information reinforces the importance of preparation of the surface when recementing.
What, then, might be a plausible explanation for the bond strength enhancement observed at a well-prepared interface? It is known that in hardened cement residual benzoyl peroxide activator is present (Charnley 1970). With the application of fresh cement, this residual activator may react with the newly added initiator, dimethyltoluidine, and monomer to start polymerisation with any residual monomer in the old cement. Rasping the surface of the old cement not only increases the area of contact, but may expose residual activator and monomer with which the fresh cement can react.

Prolongation of the preparation time of fresh cement reduces the strength of the composite interface (Fig. 6). The reason may be that monomer is continuously lost from the surface of the mixture (Lee and Ling 1975). It is also known that liquid monomer can dissolve hardened polymer. The inference is that when freshly polymerising cement contacts old cement soon after mixing, a greater amount of monomer may be present to interact with it. The close correlation between loss of monomer and interface strength (Fig. 7), further demonstrates the importance of the presence of monomer during recementing; the early use of freshly polymerising cement aids good fixation.

This work has been aided by a grant from the Orthopaedic Research and Education Foundation. The authors also wish to express their gratitude to Mr James D. Black, jun., B.Sc., for his technical assistance in these studies.

\section{REFERENCES}

Amstutz, H. C. (1970) Complications of total hip replacements. Clinical Orthopaedics and Related Research, 72, 123-137.

Chapchal, G. J., Sloofi, T. J. J. H., and Nollen, A. D. (1973) Results of total hip replacement. Clinical Orthopaedics and Related Research, 95, $111-117$.

Charnley, J. (1964) The bonding of prostheses to bone by cement. Journal of Bone and Joint Surgery, 46-B, 518-529.

Charnley, J. (1965) A biochemical analysis of the use of cement to anchor the femoral head prosthesis. Journal of Bone and Joint Surgery, 47-B, 354-363.

Charnley, J. (1970) Acrylic Cement in Orthopaedic Surgery. Edinburgh and London: E. \& S. Livingstone Ltd.

Charnley, J. (1976) Personal communication.

Coventry, M. B. (1975) Treatment of infections occurring in total hip surgery. Orthopedic Clinics of North America, 6, $991-1003$.

Eftekhar, N. S. (1974) Complications of total hip replacement. Part 3. Mechanical failure in low-friction arthroplasty. American Academy of Orthopaedic Surgeons Instructional Course Lectures, volume 23, pp. 230-242. St Louis: C. V. Mosby.

Galante, J. (1971) Total hip replacement. Orthopedic Clinics of North America, 2, 139-155.

Greenwald, A. S., Combs, S. P., Wilde, A. H., Fleck, W. G., and Black, J. D., jun. (1975) Comparative studies of the bonding strength of new and old acrylic bone cements. Surgical Forum, 26, 505-506.

Lee, A. J. C., and Ling, R. S. M. (1975) Further studies of monomer loss by evaporation during the preparation of acrylic cement for use in orthopaedic surgery. Clinical Orthopaedics and Related Research, 106, 122-125.

Lowell, J. D. (1974) Complications of total hip replacement. Part 2. American Academy of Orthopaedic Surgeons Instructional Course Lectures, volume 23, pp. 209-230. St Louis: C. V. Mosby. 